\title{
Post-marketing surveillance of anti-malarial medicines used in Malawi
}

\author{
Ibrahim Chikowe ${ }^{1,2}$, Dorcas Osei-Safo ${ }^{1 *}$, Jerry JEK Harrison ${ }^{1}$, Daniel Y Konadu ${ }^{1}$ and Ivan Addae-Mensah ${ }^{1}$
}

\begin{abstract}
Background: The growing concern over the extent of anti-malarial medicine resistance in sub-Saharan Africa, driven largely by administration of sub-therapeutic doses derived from falsified and substandard medicines necessitates regular monitoring of the quality of these medicines to avert any potential public health disaster. This study aimed at determining the active pharmaceutical ingredient (API) content of anti-malarial medicines available in Malawi with respect to the manufacturers' label claim and pharmacopoeia specifications.

Methods: Samples of anti-malarial medicines (112) collected from both licensed and unlicensed markets throughout Malawi were subjected to visual inspection of dosage form and packaging, and registration verification with the regulatory body. Basic (colourimetric) tests were employed to establish the presence and identity of the requisite APIs. Semi-quantitative thin layer chromatography (SQ-TLC) was employed as a quick assay for the verification of identity and estimation of the API content while HPLC assays were used to quantify the APIs. The results were compared with pharmacopoeia specifications and manufacturers' label claims. For combination therapies, a sample was considered to have failed if one or more of its component APIs did not meet pharmacopoeia specifications.
\end{abstract}

Results: There was $86.6 \%$ registration status and 100\% compliance with visual inspection and basic tests confirming the presence of requisite APIs. The identification test was confirmed by the SQ-TLC assay. API quantification by HPLC assay however, showed that $88.4 \%$ (99/112) of the samples failed the quality tests due to the presence of either insufficient or excessive API.

Conclusions: The results suggest the existence of substandard anti-malarial medicines in Malawi. The presence of both excessive and insufficient artemisinin-based and non-artemisinin-based API, clearly points to poor adherence to GMP and improper handling during storage or distribution. The country relies heavily on imported anti-malarial medicines so there is an urgent need to carry out regular and thorough post-market surveillance of medicines to ensure better quality health care delivery.

Keywords: Malawi, Anti-malarial medicines, Substandard, API, Post-marketing surveillance

\section{Background}

No other disease has killed more humans than malaria [1] and it is still claiming millions of lives worldwide. Approximately 3.2 billion people - about half of the world's population - are at risk of malaria. In 2013, about 198 million cases were reported worldwide with an estimated 584,000 deaths. The WHO African Region recorded 90\% of these deaths, mostly among children under five years of age [2]. Although, preventive and control measures introduced since 2000 are yielding positive results, leading to

\footnotetext{
* Correspondence: dosafo@ug.edu.gh

'Department of Chemistry, University of Ghana, Legon, Accra, Ghana

Full list of author information is available at the end of the article
}

the reduction of mortality rates by $47 \%$ globally and $54 \%$ in Africa, the disease continues to be a major public health problem in most malaria-endemic countries [2]. As in most of sub-Saharan Africa [2], one hundred percent of the population in Malawi lives in a region of high malaria transmission. There is an estimated five million cases annually; responsible for about $30 \%$ of the outpatients treated at health facilities and about $40 \%$ of all hospitalizations of children under five years of age [3].

Malaria control strategic plans in Malawi comprise the following four key interventions: prompt access to ACT, intermittent preventive treatment during pregnancy (IPTP), long-lasting insecticide-treated nets (LLITNs), 
and indoor spraying with residual insecticides [3]. Since 2007, artemether-lumefantrine has been adopted as the first-line treatment for uncomplicated and unconfirmed cases, after replacing sulphadoxine-pyrimethamine (SP), which also replaced chloroquine in 1993 due to parasite resistance. SP and other anti-malarial medicines, such as quinine (QN), are still being used for special cases [2].

Plasmodium resistance to malaria treatment has several devastating effects. It has led to an increase in morbidity and mortality rate, parasite transmission, severity of the pandemic and change in malaria distribution. As a result, this has caused pressure on the economy due to increase in cost of health services arising from prevalent treatment failures and deaths [4]. Thus, patients resort to illegal medicines, exposing them to poor quality medicines. Fake/spurious/substandard/degraded/counterfeit medicines are mostly blamed for the escalation of medicine resistance. For example, some pockets of parasite resistance to artemisinin-based medicines have been attributed to the sub-therapeutic doses derived from falsified and substandard medicines [5]. Various studies have reported the widespread circulation of poor quality medicines in some parts of Asia and Africa. Most of them have been shown to contain sub-therapeutic amounts of the APIs or no API at all or even toxic compounds [6-8].

Currently, the only hope for future malaria treatment rests on artemisinin-based combination therapy (ACT). However, with the high demand and cost of production of these medicines, the poor regulatory systems that exist in most endemic countries including Malawi allow unscrupulous persons to easily infiltrate the weak chain supply systems with both imported and/or domestic poor quality medicines $[9,10]$. Therefore, it is imperative to protect these medicines from any impending medicine resistance through GMP, relentless combat against the circulation of poor quality medicines and strict patient compliance to treatment regimen.

The WHO Expert Committee on Quality Assurance of Medicines calls for routine quality control activities to check this malpractice. Therefore, this study aimed at evaluating the quality of the anti-malarial medicines used in Malawi with respect to the active pharmaceutical ingredient (API) content in both ACT and nonACT. To achieve this aim, the following specific objectives were set: to find out the registration status of the antimalarial medicines available on the markets; to visually inspect dosage forms and packaging using the guidelines outlined in the WHO pharmacopoeia and the literature; to carry out a qualitative determination to establish the presence or otherwise of the APIs using the authenticated rapid tests outlined in the WHO publications; to carry out a quantitative determination of the API content.

\section{Methods}

\section{Sampling procedures}

Samples were collected by the first author after seeking permission from the regulatory boards; the Pharmacy, Medicines and Poisons Board and the National Health Sciences Research Committee (NHSRC) of Malawi. The medicines were bought under the guise of a patient, but in the case where pharmacy technicians refused to sell without prescription or many brands of medicine were being bought at once, it was explained that they were for research purposes. In the situation where the investigator introduced himself as a researcher, he ensured that he was sold the medicines from the open shelves to avoid a tendency where vendors give out only authentic goods to regulatory authorities or researchers.

The country was divided into four zones based on the National Malaria Control Programme (NMCP) strategy partitions designated as south west (1), south east (2), central (3) and north (4) zones. Few districts from each zone were selected based on malaria prevalence rates, economic activities and geographical position (border towns). A master list of pharmacies and private health facilities in the districts of interest was compiled. The pharmacies were considered based on proportionate sampling, called probability proportionality to size (PPS), i.e. more samples from districts with more pharmacies/ health facilities. The districts of Lilongwe, Mzuzu and Blantyre were further divided into Enumeration areas (EAs) as these had pharmacies in separate townships as well, unlike the other districts that had few pharmacies/ private health facilities all clustered at one place. Each township acted as an EA. The simple random sampling (SRS) procedures were used to select the EAs because the EAs were few per district. The random walk method was used in the selection of pharmacies/health facilities from the EAs while for the rest of the districts all pharmacies were selected as there were few pharmacies. Samples were collected between December and January (within the rainy season of November to April) when Malawi records peak malarial transmission due to abundance of stagnant water points, which are favourable breeding grounds for the mosquito vector. The antimalarial medicines were purchased from both licensed and unlicensed markets such as private pharmacies and hospitals, street vendors and shops. The samples were purchased regardless of size, company name, brand, product name, dosage form and strength, though not more than one sample of the same name, batch number and characteristics were bought at one outlet. They were labelled, recorded and kept in containers that protected them from extreme light, moisture, crushing, heat and mechanical shock. For more details of the samples see Additional file 1. The sampling sites are shown in Additional file 2. 


\section{Reference standards}

The Reference standards were purchased from the European Directorate for the Quality of Medicines and Healthcare (EDQM), France.

\section{Medicine analysis \\ Registration verification and visual inspection}

The samples were subjected to registration verification with the medicine regulatory authority - the Pharmacy, Medicines and Poisons Board of Malawi after the collection exercise. This was followed by visual inspection with respect to technical regulatory information as outlined in the WHO International Pharmacopoeia $[11,12]$.

\section{Basic/Colourimetric tests}

To determine if the samples contained the APIs claimed by the manufacturers on the packaging materials, all of them were subjected to colourimetric tests using the suitable reactions and reagents outlined in the pharmacopoeias and the literature [13-15].

Semi-quantitative thin layer chromatography (SQ-TLC) assay SQ-TLC was employed as a quick assay for the verification of identity and estimation of the API content in the medicine samples according to published protocols $[16,17]$.

\section{HPLC assay}

HPLC procedures suitable for determining the API in each anti-malarial sample adopted from the pharmacopoeias and the literature [17-21] were employed. Calibration curves were prepared using varying concentrations of the various Reference Standards (RS). The Area Under the Curve (AUC) for each concentration was determined from six replicates and an average AUC was obtained. This data was used to generate calibration curves of a plot of average AUC against concentration (C) using Microsoft Excel and the slope of the graph, intercept, correlation coefficient $\left(r^{2}\right)$ as well as equation of the straight line, AUC = $\mathrm{mC}+\mathrm{b}$ were deduced and calculated. The quantities of the APIs in the medicine samples then were calculated from their corresponding calibration curves. Six replicates were carried out for each API component and the mean and standard deviations were calculated (see Additional files 3 and 4).

\section{Assay for artesunate in ATS/SP and ATS/SmP samples}

The assay for ATS was adopted from Ranher et al. [18] with a few modifications as follows: column measurements: Discovery C-18 bonded, $5 \mu \mathrm{m}, 25 \mathrm{~cm} \mathrm{x} 4 \mathrm{~mm}$; mobile phase: 70: $30 \mathrm{v} / \mathrm{v}, 1 \%$ triethylamine (TEA) in methanol: buffer $\left(10 \mathrm{mM} \mathrm{KH} \mathrm{PO}_{4} / 85 \% \mathrm{H}_{3} \mathrm{PO}_{4}, \mathrm{pH}=\right.$ 2.5); retention time (average): 5.1 minutes; detection wavelength: $216 \mathrm{~nm}$; flow rate: $1.2 \mathrm{~mL} / \mathrm{min}$; volume of injection: $20 \mu \mathrm{L}$. For each ATS-containing sample, a quantity of the powdered dosage form equivalent to $10 \mathrm{mg}$ of artesunate was weighed into a clean dry $10 \mathrm{~mL}$ volumetric flask. $5 \mathrm{~mL}$ of the mobile phase was then added and the mixture shaken for 15 minutes on an ultrasonic sonicator. Then, more mobile phase was added to the mark and the solution filtered through a $0.45 \mu \mathrm{m}$ filter.

\section{Assay for artemether and lumefantrine in ATM/LUM samples}

The assay protocol for ATM and LUM was derived from modifications of a method developed by Arun and Smith [19]. The adapted method is as follows: column measurements: Hyperprep PEP 300A C4, $25 \mathrm{~cm} \mathrm{x} 4.6 \mathrm{~mm}$, $8 \mu \mathrm{m}$; mobile phase: $70: 30 \mathrm{v} / \mathrm{v}$ acetonitrile: $10 \mathrm{mM}$ buffer consisting of $\mathrm{KH}_{2} \mathrm{PO}_{4}$ mixed with $1 \mathrm{~mL}$ of triethylamine per liter and $\mathrm{pH}$ changed to 2.5 using $85 \% \mathrm{H}_{3} \mathrm{PO}_{4}$ mixture; retention time (average): ATM 2.5 minutes, LUM 3.0 minutes; detection wavelength: $216 \mathrm{~nm}$; flow rate: $1.5 \mathrm{~mL} / \mathrm{min}$; volume of injection: $20 \mu \mathrm{L}$. The counter-ion modifying agent triethylamine was added to obtain enhanced peak symmetry and minimize tailing. Furthermore, due to the large difference in the ratio of ATM to LUM (1:6), efforts were made to add a detectable amount of ATM without unnecessarily overloading the column with high concentrations of LUM. Sample solutions of the tablets were prepared by accurately weighing $4 \mathrm{mg}$ of the powdered dosage form weighed into a clean dry beaker. $1 \mathrm{~mL}$ of acetic acid was added, allowed to react for a few minutes after which $5 \mathrm{~mL}$ of the mobile phase was added. The mixture was then shaken for 15 minutes on an ultrasonic sonicator, filtered into a $10 \mathrm{~mL}$ volumetric flask through a $0.45 \mu \mathrm{m}$ filter, and made up to the mark through the filter with the mobile phase.

\section{Assay for dihydroartemisinin in DHA/SP and DHA/Pp samples} A method outlined in the Ph. Int. [12] was modified as follows: column measurements: Kramasil C8, $25 \mathrm{~cm} \mathrm{x}$ $4.6 \mathrm{~mm}, 5 \mu \mathrm{m}$; mobile phase: $50: 50 \mathrm{v} / \mathrm{v}$, water: acetonitrile; retention time (average): 5.2 minutes; detection wavelength: $210 \mathrm{~nm}$; flow rate: $1.5 \mathrm{~mL} / \mathrm{min}$; volume of injection: $10 \mu \mathrm{L}$. For each sample, a quantity of powdered tablets equivalent to $10 \mathrm{mg}$ of DHA was accurately weighed into a clean dry beaker. This was extracted four times with diethyl ether as SP and Pp are practically insoluble in diethyl ether. This solution was evaporated to dryness. The residue was re-dissolved in $5 \mathrm{~mL}$ of the mobile phase, sonicated for 15 minutes, filtered through a $0.45 \mu \mathrm{m}$ filter into a $10 \mathrm{~mL}$ volumetric flask and made up to the mark.

\section{Assay for quinine in QN samples}

QN was assayed according to a modified version in USP 24 [20]. Column measurements: Discovery C-18 bonded, 
$25 \mathrm{~cm} \times 4.0 \mathrm{~mm}, 5 \mu \mathrm{m}$; mobile phase: 80:16:2:2 v/v, water: acetonitrile: methanesulfonic acid: TEA, $\mathrm{pH}$ 2.6; retention time (average): 5.7 minutes; detection wavelength: $235 \mathrm{~nm}$; flow rate: $1.2 \mathrm{~mL} / \mathrm{min}$.; volume of injection: $20 \mu \mathrm{L}$. For the suspensions and mixtures, a certain amount was sonicated for about 15 minutes and a quantity equivalent to $5 \mathrm{mg}$ was pipetted into a $10 \mathrm{ml}$ volumetric flask. Methanol $(8 \mathrm{ml})$ was added to the contents of the flask and made up to the mark with the mobile phase. Where necessary, the solution was also filtered.

For the injections, a $10 \mathrm{~mL}$ solution was prepared in a volumetric flask after 5 ampoules of quinine injections were mixed together and $20 \mu \mathrm{L}$ aliquot was measured from the stock quinine solution using a microlitre syringe. The prepared solution was diluted with $8 \mathrm{~mL}$ of methanol and the mobile phase was added to the $10 \mathrm{~mL}$ mark.

\section{Assay for sulphadoxine/sulphamethoxypyridazine and pyrimethamine}

The experimental conditions employed in the analysis of $\mathrm{S}$, Sm and P samples, were modified after a WHOadopted monograph for inclusion into the Ph. Int. in 2010 [21]. Column measurements: Ascentis C-18, $15 \mathrm{~cm} \mathrm{x}$ $4.60 \mathrm{~mm}, 5 \mu \mathrm{m}$; mobile phase: 65:10:25 v/v, $20 \mathrm{mM}$ buffer $\left(\mathrm{KH}_{2} \mathrm{PO}_{4} / \mathrm{Na}_{2} \mathrm{HPO}_{4}\right.$ of $\mathrm{pH} 5.6$; methanol; acetonitrile; retention time (average): sulphadoxine/sulphamethoxypyridazine 3.9 minutes, pyrimethamine 8.7 minutes; detection wavelength: $240 \mathrm{~nm}$; flow rate: $1 \mathrm{~mL} / \mathrm{min}$; volume of injection: $10 \mu \mathrm{L}$. Solutions of sulphadoxine/sulphamethoxypyridazine and pyrimethamine containing tablets were prepared as follows: a quantity of the powdered dosage form equivalent to $100 \mathrm{mg}$ of sulphadoxine/sulphamethoxypyridazine and $5 \mathrm{mg}$ of pyrimethamine were weighed simultaneously into a clean dry beaker. The APIs were extracted three times for completeness using acetonitrile and finally made up to the mark with the mobile phase in a $50 \mathrm{~mL}$ volumetric flask.

\section{Validation}

Accuracy, precision, linearity and specificity parameters were evaluated for all the various determinations. Accuracy of results of an analytical method can also be established when validation parameters including precision (RSD values), linearity ( $\mathrm{R}^{2}$ values), accuracy (\% recovery) and specificity (retention times) were evaluated for all the various determinations $(n=6)$.

\section{Data interpretation}

Poor quality medicines may be degraded, substandard or counterfeit. According to the WHO, Spurious/FalselyLabelled/ Falsified/Counterfeit (SFFC) medicines (branded or generic) can be classified as "any medicines or pharmaceutical products that are deliberately and fraudulently mislabelled for identity and/or source" The definition includes products with correct or wrong ingredients, without active ingredients, with insufficient active ingredients, or with false packaging [22]. Substandard medicines, also known as Out of Specification (OOS) products are those that are genuine and legally produced but fall outside the specifications or acceptance criteria established in product dossiers, drug master files, pharmacopoeias or by the manufacturer. A degraded medicine can be classified along with substandard medicine. However, they differ in that they might be originally of specification, but in the course of time naturally or catalysed by external factors, fall out of specification within its shelf-life [5].

In this study, a sample was considered to have failed the quality evaluation if it did not meet any of the following criteria: 1) failure of visual inspection of dosage form and packaging, 2) failure to produce the expected colour reaction in the basic test and 3) failure to produce the expected spot colour or $\mathrm{R}_{\mathrm{f}}$ on TLC compared to the reference standard. With respect to API content, a component API was classified as "compliant (C)" if its quantity fell within the acceptable International Pharmacopoeia limits of $90-110 \%$ of the amount of API stated on the label claim; "non-compliant (NC)" if the quantity was less than the lower (insufficient) or more than upper (excessive) acceptable limits $[11,12]$. Thus an ACT was considered compliant or to have passed the API content test only when both or all of its component APIs were compliant.

\section{Results}

\section{Sample description}

The anti-malarial samples analysed were 112, comprising 36 non-ACT, 4 ACT of single dose medicines co-packed on the same blister to be taken concomitantly and 72 ACT of fixed dose combinations. Artemether-lumefantrine (ATM/ LUM) tablets, being the main ACT and serving as the firstline treatment for malaria in the country, formed the bulk of samples (36.6\%) while SP tablets represented $20.5 \%$. The formulations also included suspensions, injections and mixtures containing other APIs such as quinine $(\mathrm{QN})$, piperaquine (Pp), sulphamethoxypyridazine (Sm), artesunate (ATS) and dihydroartemisinin (DHA). A total of 153 samples were collected, but the number analysed was limited by available assays and reference standards (RS). Table 1 shows a summary of the samples collected and analysed.

\section{Registration status of samples}

The samples were subjected to registration verification with the Pharmacy, Medicine and Poisons Board of Malawi as soon as the collection exercise was completed. As of 31st December, 2011, 86.6\% (97/112) of the collected samples as well as their formulation types were registered with the regulatory board, according to their 
Table 1 Categories of collected anti-malarial medicine samples

\begin{tabular}{|c|c|c|c|c|c|}
\hline \multicolumn{2}{|l|}{ Non-ACT } & \multicolumn{2}{|l|}{$\begin{array}{l}\text { ACT co-packed } \\
\text { on one blister }\end{array}$} & \multicolumn{2}{|c|}{ Fixed dose ACT } \\
\hline API & No. & API & No. & API & No. \\
\hline Quinine sulphate & 6 & \multirow{4}{*}{$\begin{array}{l}\text { ATS co-packed } \\
\text { with SP }\end{array}$} & \multirow[t]{4}{*}{4} & ATM/LUM & 41 \\
\hline Quinine hydrochloride & 3 & & & DHA/Pp & 14 \\
\hline Quinine bisulphate & 4 & & & DHA/SP & 12 \\
\hline SP & 23 & & & ATS/SmP & 5 \\
\hline TOTAL & 36 & & 4 & & 72 \\
\hline
\end{tabular}

ATM, artemether; ATS artesunate; LUM, lumefantrine; DHA, dihydroartemisinin; $\mathbf{S}$, sulphadoxine; $\mathbf{P}$, pyrimethamine; $\mathbf{P p}$, piperaquine phosphate; Sm, sulphamethoxypyridazine.

annual registration publication. None of the samples was manufactured locally; all of them were imported samples with $60.7 \%$ manufactured in India and the rest originating from China, Kenya and Tanzania.

\section{Visual inspection of dosage form and packaging}

The visual inspection of the dosage forms and packaging showed total (100\%) compliance of the samples with the requirements. Labelling information regarding dosage form, brand name, active ingredient/strength, batch number, manufacture and expiry dates were provided (see Additional file 1). Tablets did not present with non-uniform colouration or signs of breakage.

\section{Basic tests}

API content claims were confirmed by colourimetric tests, which demonstrated that all the samples contained the requisite APIs claimed by the manufacturers. However, it has been reported that with the advancement of counterfeiting, visual inspection and basic tests alone cannot qualify a medicine as genuine despite chemical and physical similarities. According to Bate et al., the determination of a medicine as counterfeit or substandard requires a forensic examination of the trademarks; product designs and holograms [23], but the present study did not go as far as that.

\section{HPLC assay}

A major challenge in the simultaneous assay of ATM/LUM tablets was the choice of a solvent that would not interfere with the analyte peaks, dissolve both APIs long enough for the analysis to be carried out and also give well-resolved peaks. This was overcome by using acetic acid followed
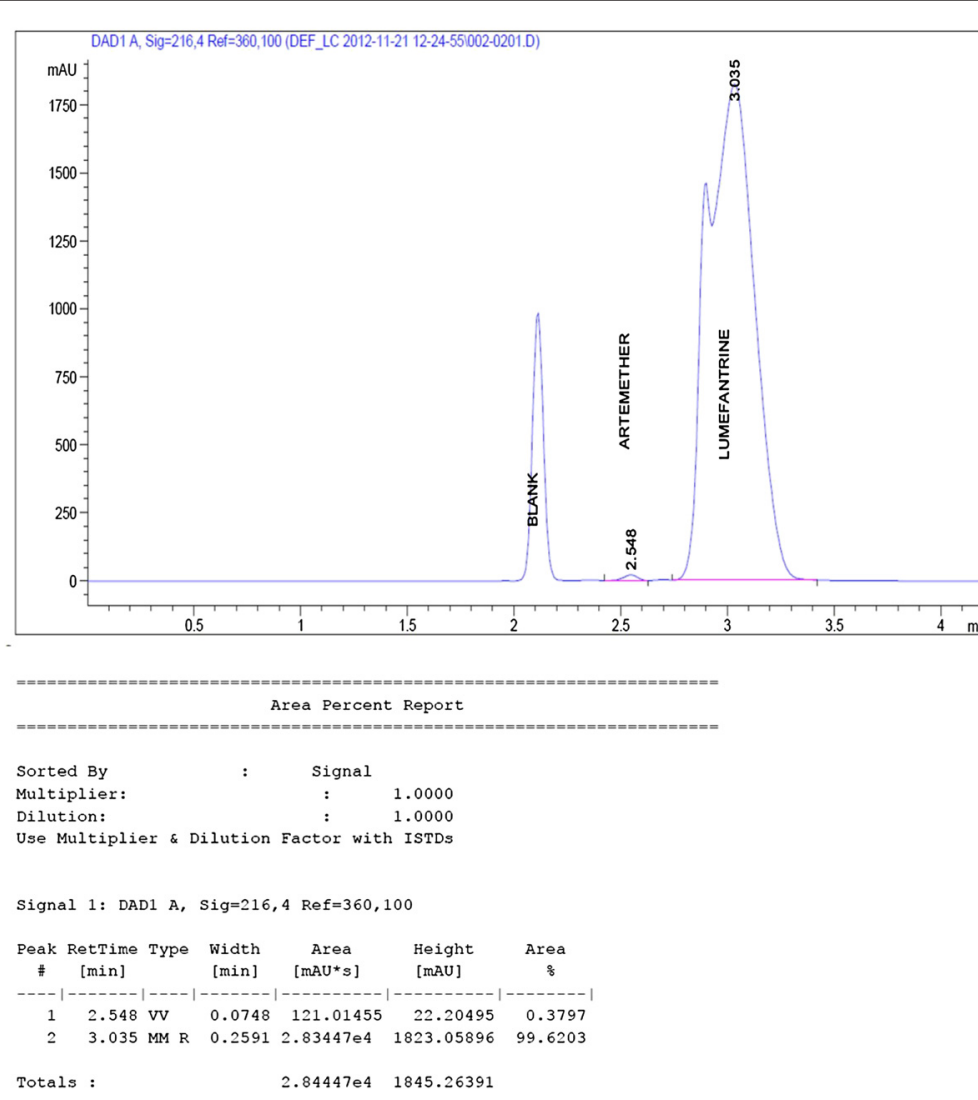

Figure 1 Chromatogram of a $0.3 \mathrm{mg} / \mathrm{mL}$ and $1.7 \mathrm{mg} / \mathrm{mL}$ of ATM and LUM RS solutions. 


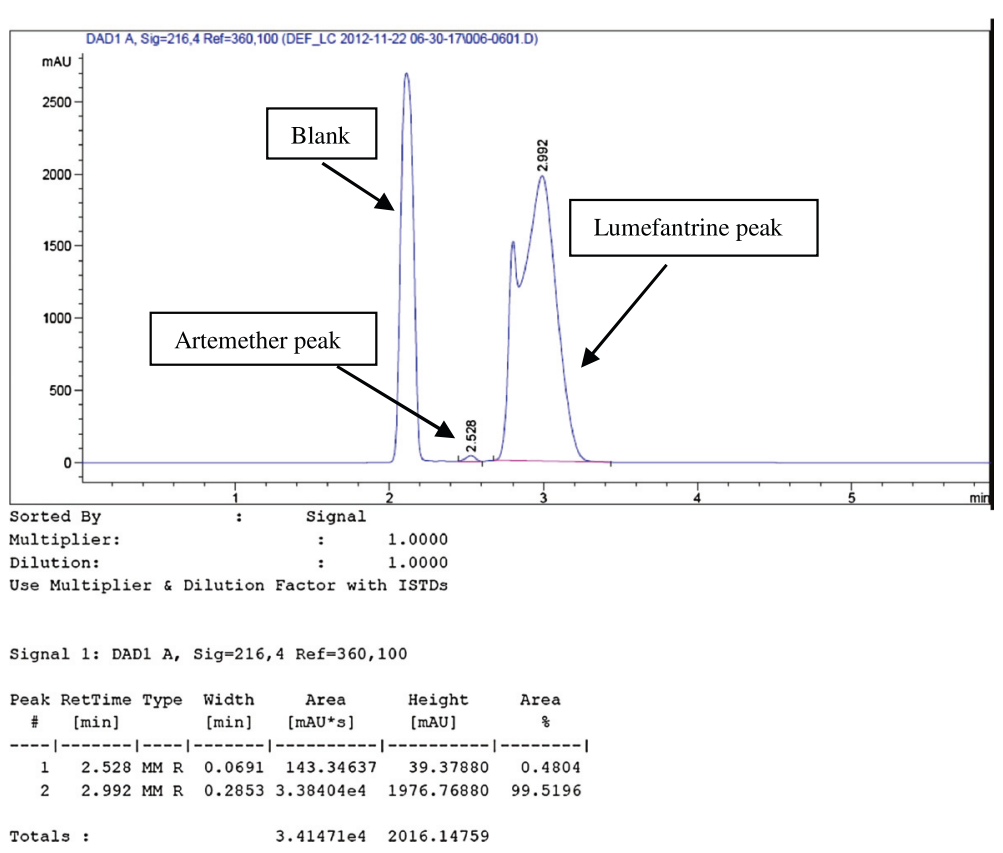

Figure 2 Chromatogram for ATM/LUM tablet.

by acetonitrile to extract the active ingredients. From the chromatograms, acetic acid eluted first and did not interfere with the analyte peaks. Acetonitrile, with its low cut-off wavelength also did not interfere. The addition of the modifying agent triethylamine greatly enhanced peak symmetry and minimized tailing. A small shoulder appeared in the LUM peak and was observed in both the RS and the samples. Its presence did not hinder the computation of the AUC and was attributed to the column type, the mobile phase composition or both (Figures 1 and 2). Another challenge encountered was the difficulty in detecting artemether due to its low molar absorptivity and its low concentration $(16.7 \%)$ in the fixed dose combination. Thus in the preparation of the calibration curves, different LUM concentrations were tried to obtain a range that would allow for the suitable detection of ATM and at the same time, not correspond to too high concentrations of LUM. The curves obtained were linear with $\mathrm{R}^{2}$ values of 0.994 for ATM and 0.993 for LUM (Figures 3 and 4).

The assay of SP samples was also problematic with respect to the high ratio of sulphadoxine to pyrimethamine, 20:1 respectively. Suitably high concentrations of sulfadoxine API were used to aid in the detection of pyrimethamine. The calibration curves obtained were linear with an $\mathrm{R}^{2}$ value of 0.999 and 0.998 for sulfadoxine and pyrimethamine respectively (Table 2). Details and sample chromatograms of all samples assayed together with their corresponding calibration curves are presented in Additional files 3 and 4.

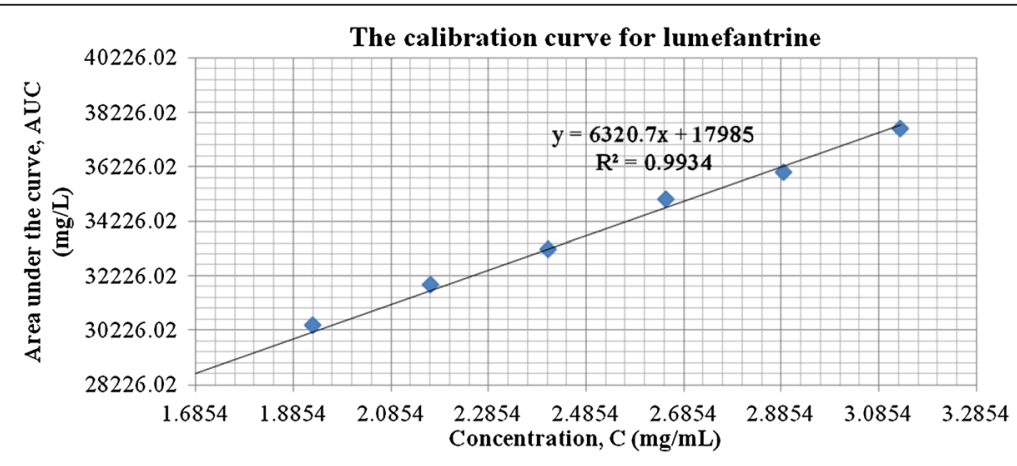

Figure 3 Calibration curve for lumefantrine. 


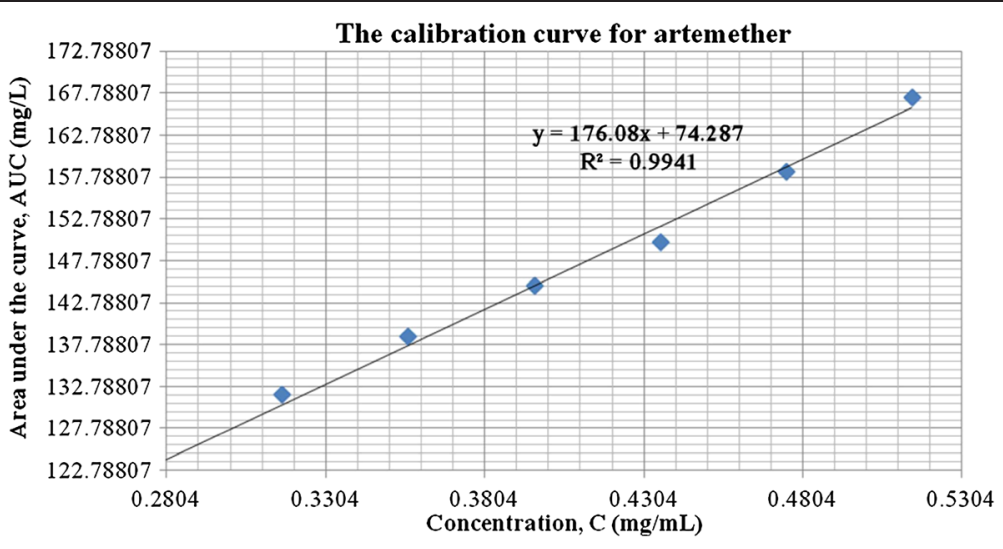

Figure 4 Calibration curve for artemether.

\section{Validation}

The accuracy of results of an analytical method can be established when validation parameters such as precision, linearity and specificity are clearly demonstrated. A summary of the method validation results is presented in Table 2, with details in Additional file 4. The average RSD values are $\leq 2 \%$. The linearity values $\left(R^{2}\right)$ are also above 0.95 demonstrating a very good correlation between the peak area (AUC) and the concentration of the analyte APIs, linear across the $80-120 \%$ RS concentrations. The retention times of the analyte in the sample and the RS are also comparable, demonstrating high specificity.

\section{Quality of anti-malarial medicines}

Although all the samples passed the visual inspection and qualitative determination tests, the HPLC assay revealed that $88.4 \%(99 / 112)$ did not meet the requirements for API content (Table 3). The main cause of the failure was either the presence of insufficient API (i.e. $<90 \%)$ or excessive API $(>110 \%)$. See Additional file 3 for detailed results.

The 112 anti-malarial samples consisted of 9 APIs in various combinations with the exception of $\mathrm{QN}$, which occurred as a monotherapy. Pp could not be assayed due to unavailability of a reference standard. Out of the 4 ATS/SP samples, ATS was compliant in all, P was compliant in 2 samples while $S$ was compliant in none. The total noncompliance of the $S$ component thus resulted in a $100 \%$ failure of all the ATS/SP samples.

ATS was compliant in only 2 out of the 5 ATS/SmP samples while Sm and P were compliant in 1 and 2 samples respectively. Regardless of having at least one case of compliance for each constituent API, this did not occur in the same sample. Hence, there was not a single sample in which all the individual APIs were compliant, resulting in $100 \%$ failure. In the 23 SP samples, compliance for $\mathrm{S}$ and $\mathrm{P}$ was in 3 and 12 samples respectively. Compliance for both constituents occurred together in only 2 samples resulting in $91.3 \%$ failure rate. There were $12 \mathrm{DHA} / \mathrm{SP}$ samples and although API content test for $\mathrm{P}$ was $100 \%$ compliant, 11 samples failed the S API content test while DHA was $100 \%$ noncompliant. Hence, no DHA/SP sample passed the quality test. Since Pp API in DHA/Pp could not be assayed, based on DHA alone, 4 out of the 14 samples were compliant (71.4\% failure rate). In the case of the $41 \mathrm{ATM} / \mathrm{LUM}$ samples, only 2 samples had both APIs being compliant in the same sample. Overall, ATM was compliant in 14 samples while LUM was compliant in 11 samples. The failure

Table 2 Results of analytical method validation

\begin{tabular}{llllllll}
\hline Validation parameter & ATM & ATS & DHA & LUM & QN & S \\
\hline Precision (RSD) & 0.836023149 & 0.088086277 & 1.165330278 & 0.896337033 & 2.00605798 & 1.77262931 & 0.0030604 \\
Linearity(R $\left.{ }^{2}\right)$ & 0.9940 & 0.9941 & 0.9950 & 0.9934 & 0.9979 & 0.9993 & 0.9975 \\
Slope & 176 & 502 & 410.1 & 6320 & 20180 & 16929 & 16600 \\
Intercept & 74.28 & 52.65 & 31.35 & 17985 & 162.9 & 4894 & 948.09 \\
Specificity (Retention time) & & & & & 3.113 & 3.928 & 8.689 \\
Medicine Sample API & 2.528 & 5.081 & 5.225 & 2.992 & 3.928 & 8.689 \\
Reference Standard & 2.548 & 5.091 & 5.225 & 3.035 & 6.113 & 3.928 \\
\hline
\end{tabular}




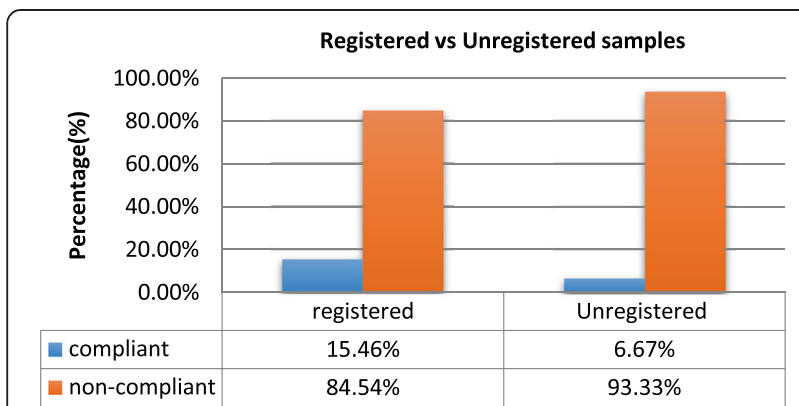

Figure 5 A comparison of failure rates for registered and unregistered samples.

rate of the samples was $91.5 \%$. In the $13 \mathrm{QN}$ monotherapy, $61.5 \%$ of the samples failed the quality test.

Failure rate of anti-malarial medicines versus registration status Comparison of the failure rate of registered and unregistered samples suggested that registration status did not have significant influence on the quality of the anti-malarial medicines. Out of the 97 registered samples, $15.5 \%$ (15) of the samples were compliant, while $6.7 \%$ (1) of the 15 unregistered samples were compliant. Although the registered samples had a slight edge over the unregistered ones, the overall results (Figure 5) show that registration status does not necessarily always guarantee the quality a drug. These results are similar to the observations made in the 2008/2009 Ghana study [16].

\section{Samples with the same batch number}

API content of samples within same batches was compared to ascertain their uniformity. Some of the batch numbers were unregistered while others were duly registered. The results (Table 4) revealed wide variations in API content within batches, regardless of registration status.

\section{Reporting of results}

The findings of the study have not yet been made available to any of the regulatory bodies - the Pharmacy, Medicines and Poisons Board, the National Health Sciences Research Committee (NHSRC) of Malawi or the WHO Rapid Alert System.

\section{Discussion}

The study showed a good correlation between both visual inspection of dosage form and packaging material on one hand and qualitative determination (basic tests) of API on the other because the labelled contents on the packaging materials were found to be correct. Thus, none of the samples can be considered as falsified with respect to visual inspection and qualitative determination. However, the quantitative assay revealed noncompliance of API content in a significant majority of the samples. There were 145 instances of the presence of a noncompliant API in the various categories of the antimalarial medicines against 73 cases of compliance. In the combination formulations, more often than not,

Table 3 Level of compliance of individual API content and failing rates of anti-malarial samples

\begin{tabular}{|c|c|c|c|c|c|c|}
\hline \multirow{2}{*}{$\begin{array}{l}\text { Anti-malarial } \\
\text { sample }\end{array}$} & \multirow{2}{*}{$\begin{array}{l}\text { Number of } \\
\text { samples }\end{array}$} & \multicolumn{3}{|c|}{ Level of compliance of API content } & \multirow[t]{2}{*}{ Remarks } & \multirow{2}{*}{$\begin{array}{l}\text { Number and rate } \\
\text { of failing samples }\end{array}$} \\
\hline & & API & compliant & noncompliant & & \\
\hline \multirow[t]{3}{*}{ ATS/SP } & 4 & ATS & 4 & 0 & \multirow[t]{3}{*}{ All the 4 samples were noncompliant } & \multirow[t]{3}{*}{$4(100 \%)$} \\
\hline & & $S$ & 0 & 4 & & \\
\hline & & $P$ & 2 & 2 & & \\
\hline \multirow[t]{3}{*}{ ATS/SmP } & 5 & ATS & 2 & 3 & \multirow{3}{*}{$\begin{array}{l}\text { Compliant APIs did not occur in the } \\
\text { same samples therefore all the samples } \\
\text { were noncompliant }\end{array}$} & \multirow[t]{3}{*}{$5(100 \%)$} \\
\hline & & $\mathrm{Sm}$ & 1 & 4 & & \\
\hline & & $P$ & 2 & 3 & & \\
\hline \multirow[t]{2}{*}{ ATM/LUM } & 41 & ATM & 14 & 27 & \multirow{2}{*}{$\begin{array}{l}\text { Only } 2 \text { samples had both APIs being } \\
\text { compliant in the same sample. }\end{array}$} & \multirow[t]{2}{*}{$39(95.1 \%)$} \\
\hline & & LUM & 11 & 30 & & \\
\hline \multirow[t]{2}{*}{$\mathrm{DHA} / \mathrm{Pp}$} & 14 & $\mathrm{DHA}$ & 4 & 10 & \multirow{2}{*}{$\begin{array}{l}\text { Pp API could not be assayed. Based on DHA } \\
\text { alone, } 4 \text { out of } 14 \text { samples were compliant }\end{array}$} & \multirow[t]{2}{*}{$10(71.4 \%)$} \\
\hline & & $\mathrm{Pp}$ & - & - & & \\
\hline \multirow[t]{3}{*}{ DHA/SP } & 12 & $\mathrm{DHA}$ & 0 & 12 & \multirow{3}{*}{$\begin{array}{l}\text { All the samples were noncompliant even } \\
\text { though P was 100\% compliant }\end{array}$} & \multirow[t]{3}{*}{$12(100 \%)$} \\
\hline & & S & 1 & 11 & & \\
\hline & & $P$ & 12 & 0 & & \\
\hline \multirow[t]{2}{*}{ SP } & 23 & S & 3 & 20 & \multirow{2}{*}{$\begin{array}{l}\text { Only } 2 \text { samples had both APIs being } \\
\text { compliant in the same sample }\end{array}$} & \multirow[t]{2}{*}{21 (91.3\%) } \\
\hline & & $P$ & 12 & 11 & & \\
\hline QN & 13 & QN & 5 & 8 & 5 out 13 samples were compliant & $8(61.5 \%)$ \\
\hline Total & 112 & & 73 & 145 & & $99(88.4 \%)$ \\
\hline
\end{tabular}


Table 4 Samples with the same batch number and their respective API content

\begin{tabular}{|c|c|c|c|c|c|c|c|c|}
\hline \multirow{2}{*}{$\begin{array}{l}\text { Anti-malarial sample showing API } \\
\text { and strength } \\
\text { SDX/PYR }\end{array}$} & \multirow{2}{*}{$\begin{array}{l}\text { Batch No. } \\
\text { S-60 }\end{array}$} & \multicolumn{7}{|c|}{ Samples with the same batch number and their respective API content with HPLC assay } \\
\hline & & $1_{4} \mathrm{P}_{10}{ }^{*}$ & $1_{6} \mathrm{P}_{10}{ }^{*}$ & $1_{1} P_{10}{ }^{*}$ & $3_{1} P_{10}^{*}$ & $3_{2} \mathrm{P}_{10}{ }^{*}$ & $3_{3} \mathrm{P}_{10}{ }^{*}$ & \\
\hline $500 / 25 \mathrm{mg}$ & & $425 / 28 \mathrm{mg}$ & $415 / 23 \mathrm{mg}$ & $390 / 23 \mathrm{mg}$ & $415 / 21 \mathrm{mg}$ & $405 / 24 \mathrm{mg}$ & $410 / 22 \mathrm{mg}$ & \\
\hline SDX/PYR & 1001 & $1_{1} P_{2}$ & $1_{4} \mathrm{P}_{2}$ & $2 P_{2}$ & $3_{5} \mathrm{P}_{2}$ & & & \\
\hline $500 / 25 \mathrm{mg}$ & 1 & $435 / 29 \mathrm{mg}$ & $410 / 23 \mathrm{mg}$ & $385 / 22 \mathrm{mg}$ & 265/12 mg & & & \\
\hline SDX/PYR & 1000 & $3{ }_{1} P_{2}$ & $4_{4} \mathrm{P}_{2}$ & $1_{2} P_{2}$ & & & & \\
\hline $500 / 25 \mathrm{mg}$ & 8 & $485 / 24 \mathrm{mg}$ & $426 / 26 \mathrm{mg}$ & $335 / 19 \mathrm{mg}$ & & & & \\
\hline QUN Bi-SO ${ }_{4}$ & OK & $1_{2} V_{5}$ & $4 V_{5}$ & & & & & \\
\hline $50 \mathrm{mg} / 5 \mathrm{ml}$ & 159 & $60 \mathrm{mg}$ & $56 \mathrm{mg}$ & & & & & \\
\hline ATM/LUM & LD- & $1_{12} x_{1}$ & $1_{5} x_{1}$ & ${ }_{17} x_{1}$ & & & & \\
\hline $80 / 480 \mathrm{mg}$ & 266 & $81 / 492 \mathrm{mg}$ & $54 / 532 \mathrm{mg}$ & $65 / 283 \mathrm{mg}$ & & & & \\
\hline ATM/LUM & LD- & $1_{9} X_{1}$ & $1_{13} X_{1}$ & $1_{10} X_{1}$ & ${ }_{2} \mathrm{X}_{1}$ & $4_{4} X_{1}$ & & \\
\hline $80 / 480 \mathrm{mg}$ & 259 & $83 / 545 \mathrm{mg}$ & $112 / 528 \mathrm{mg}$ & $99 / 302 \mathrm{mg}$ & 105/302 mg & $114 / 499 \mathrm{mg}$ & & \\
\hline ATM/LUM & LF- & $1_{4} X_{1}$ & $1_{6} x_{1}$ & $3_{3} x_{1}$ & $4_{3} x_{1}$ & & & \\
\hline $40 / 240 \mathrm{mg}$ & 249 & 28/276 mg & $65 / 305 \mathrm{mg}$ & $32 / 259 \mathrm{mg}$ & 70/196 mg & & & \\
\hline ATM/LUM & LN- & $1_{8} x_{1}$ & $2{ }_{1} x_{1}$ & & & & & \\
\hline $20 / 120 \mathrm{mg}$ & 450 & $33 / 95 \mathrm{mg}$ & 19/136 mg & & & & & \\
\hline ATM/LUM & LS- & $1_{2} X_{1}$ & $3_{1} x_{1}$ & $3_{2} x_{1}$ & & & & \\
\hline 20/120 mg & 39 & 24/136 mg & $18 / 140 \mathrm{mg}$ & 19/140 mg & & & & \\
\hline ATM/LUM & SB01 & $1_{2} X_{11}$ & $1_{1} x_{11}$ & & & & & \\
\hline 180/1080 mg & 001 & 186/1328 mg & 167/1372 mg & & & & & \\
\hline ATM/LUM & C052 & $3_{1} x_{11}$ & $1_{3} X_{11}$ & & & & & \\
\hline $80 / 480 \mathrm{mg}$ & $0 \mathrm{~J}$ & $31 / 569 \mathrm{mg}$ & $32 / 408 \mathrm{mg}$ & & & & & \\
\hline ATM/LUM & 1105 & $1_{2} X_{14}$ & $1_{1} X_{14}$ & $2{ }_{4} X_{14}$ & & & & \\
\hline $20 / 120 \mathrm{mg}$ & 062 & $7 / 114 \mathrm{mg}$ & $15 / 83 \mathrm{mg}$ & $11 / 141 \mathrm{mg}$ & & & & \\
\hline $\mathrm{DHA} / \mathrm{Pp}$ & PX- & $1, Z_{1}$ & $1_{6} Z_{1}$ & $2_{6} Z_{1}$ & & & & \\
\hline $40 / 320 \mathrm{mg}$ & 161 & $34 /-$ & $39 /-$ & $41 /-$ & & & & \\
\hline DHA/SDX/PYR & AP-18 & $1_{5} Z_{1}$ & $1_{3} Z_{1}$ & $1_{2} Z_{1}$ & $2_{5} z_{1}$ & $2_{1} z_{1}$ & $3_{4} Z_{1}$ & $4_{5} Z_{1}$ \\
\hline $60 / 500 / 25 \mathrm{mg}$ & & $51 / 428 / 24 \mathrm{mg}$ & $34 / 430 / 23 \mathrm{mg}$ & $\begin{array}{l}32 / 414 / \\
25 \mathrm{mg}\end{array}$ & $\begin{array}{l}31 / 434 / \\
23 \mathrm{mg}\end{array}$ & $\begin{array}{l}34 / 385 / \\
26 \mathrm{mg}\end{array}$ & $\begin{array}{l}31 / 427 / \\
25 \mathrm{mg}\end{array}$ & $\begin{array}{l}31 / 438 / \\
26 \mathrm{mg}\end{array}$ \\
\hline $\mathrm{DHA} / \mathrm{Pp}$ & 1101 & $1_{4} Z_{3}^{*}$ & $1_{2} Z_{3}^{*}$ & $1_{1} Z_{3}{ }^{*}$ & $3_{3} Z_{3}^{*}$ & $4_{4} Z_{3}{ }^{*}$ & $4_{3} Z_{3}{ }^{*}$ & $4_{1} Z_{3}{ }^{*}$ \\
\hline $40 / 320 \mathrm{mg}$ & 23 & 28 mg/- & 34 mg/- & 39 mg/- & 28 mg/- & 35 mg/- & 28 mg/- & $30 \mathrm{mg} /-$ \\
\hline DHA/SDX/PYR & AP- & $2 Z_{4}$ & $2_{3} Z_{1}$ & $3_{5} z_{1}$ & & & & \\
\hline $60 / 500 / 25 \mathrm{mg}$ & 16 & $32 / 400 / 24 \mathrm{mg}$ & $33 / 450 / 25 \mathrm{mg}$ & $\begin{array}{l}31 / 425 / \\
25 \mathrm{mg}\end{array}$ & & & & \\
\hline SDX/PYR & 1001 & ${ }_{2} \mathrm{P}_{2}$ & $2{ }_{3} P_{2}$ & $3_{2} P_{2}$ & $4_{2} P_{2}$ & ${ }_{4} \mathrm{P}_{2}$ & & \\
\hline $500 / 25 \mathrm{mg}$ & 2 & $415 / 16 \mathrm{mg}$ & $480 / 31 \mathrm{mg}$ & $425 / 24 \mathrm{mg}$ & 235/13 mg & $426 / 27 \mathrm{mg}$ & & \\
\hline SDX/PYR & 0213 & $2{ }_{1} P_{15}$ & $37 P_{15}$ & $3_{8} \mathrm{P}_{15}$ & & & & \\
\hline $500 / 25 \mathrm{mg}$ & 50 & $410 / 23 \mathrm{mg}$ & $355 / 20 \mathrm{mg}$ & $459 / 26 \mathrm{mg}$ & & & & \\
\hline ATM/LUM & LD- & $3_{4} X_{1}$ & $3{ }_{6} x_{1}$ & & & & & \\
\hline $80 / 480 \mathrm{mg}$ & 227 & $82 / 536 \mathrm{mg}$ & $84 / 496 \mathrm{mg}$ & & & & & \\
\hline ATS/SMP/PYR & 081 & $3_{1} Y_{12}$ & $4_{1} Y_{12}$ & $4_{2} Y_{12}$ & & & & \\
\hline $200 / 500 / 25 \mathrm{mg}$ & & $\begin{array}{l}178 / 217 / \\
14 \mathrm{mg}\end{array}$ & $\begin{array}{l}174 / 440 / \\
25 \mathrm{mg}\end{array}$ & $\begin{array}{l}186 / 443 / \\
29 \mathrm{mg}\end{array}$ & & & & \\
\hline ATS/SDX/PYR & TR0458 & $3_{2} Y_{13}{ }^{*}$ & $3_{4} Y_{13}{ }^{*}$ & & & & & \\
\hline
\end{tabular}


Table 4 Samples with the same batch number and their respective API content (Continued)

\begin{tabular}{|c|c|c|c|c|c|}
\hline $100 / 500 / 25 \mathrm{mg}$ & & $98 / 340 / 20 \mathrm{mg}$ & 98/370/18 mg & & \\
\hline QUN di- $\mathrm{HCl}$ & L-491 & $3_{1} Q_{6}$ & $3_{3} \mathrm{Q}_{6}$ & $4_{1} Q_{6}$ & $4_{2} \mathrm{Q}_{6}$ \\
\hline $150 \mathrm{mg} / 5 \mathrm{ml}$ & & $166 \mathrm{mg}$ & $183 \mathrm{mg}$ & $153 \mathrm{mg}$ & $84 \mathrm{mg}$ \\
\hline QUN HCl & 110433 & $4_{2} R_{4}$ & $4_{3} R_{4}$ & & \\
\hline $100 \mathrm{mg} / 5 \mathrm{ml}$ & & $151 \mathrm{mg}$ & $156 \mathrm{mg}$ & & \\
\hline ATS/SMP/PYR & 079 & $4_{3} Y_{12}$ & $4_{4} Y_{12}$ & & \\
\hline $100 / 250 / 12.5 \mathrm{mg}$ & & $78 / 218 / 14 \mathrm{mg}$ & $90 / 225 / 15 \mathrm{mg}$ & & \\
\hline
\end{tabular}

* Unregistered samples.

compliant APIs did not occur together in the same sample, resulting in the observed high failure rate in the quality evaluation (88.4\%). Although the presence of insufficient API was the main cause of failing samples, there were cases of the presence of excessive API. In two previous studies on anti-malarial samples distributed in Ghana, where low quantities of API was also identified as a major contributory factor in failing rates, the artemisinin-based components of ACT were the insufficient APIs. Thus it was deduced that manufacturers could deliberately or otherwise be reducing quantities of the more expensive API as a means of cutting down on production cost. However, in the current quality evaluation, the artemisinin-based components have been detected in excessive quantities as well. This observation suggests poor adherence to SOPs, GMPs and proper registration procedures and is corroborated by the wide differences in API quantities of samples within batches (Table 4). In either case, there is the danger of sub-therapeutic doses of the noncompliant component promoting resistance or in the case where this component is present in excessive doses, posing a risk of toxicity to patients.

Although the registration status of anti-malarials used in Malawi was found to be quite satisfactory (13.4\% unregistered), compared to countries such as Ghana and Togo where most recent studies indicated 55\% and 78\% unregistered anti-malarials in Ghana in 2008 and 2012 $[16,17]$ respectively and $17 \%$ unregistered anti-malarials in Togo in 2012 [17], it has been established that registration of a medicine with the national regulatory authority does not necessarily guarantee its quality. ATM/ LUM, SP and QN are the most commonly used medicines against malaria in Malawi, a country burdened with high transmission rate of malaria. Hence, the failure rate of these important medicines - ATM/LUM (95.1\%), SP (91.3\%) and QN (61.5\%) - is alarming considering the fact most of the malaria cases in Malawi are diagnosed without microscopic determination. Most types of fever are presumed to be malaria first, and treated as such. If indeed, such ad hoc diagnoses are also treated with substandard anti-malarials, this could lead to treatment failure and/or fast development of resistance. This inference is based on the report by Bate et al. that resistance development of chloroquine and sulphadoxine in Africa in the 1990s and the devastating impact of malaria on the people were partly due to the use of substandard medicines [23].

\section{Comparison of current results with recent results from other African countries}

Recent surveys on the quality of medicines circulating in many African countries have shown similar trends of poor quality anti-malarial medicines [7,16,17,24]. Most regulated manufacturers bypassed their GMP compliance and set the standards of their medicine products based on the recipient countries' status with regard to the level of regulation capability and level of income as well as lack of prequalified standards by most developing countries to their suppliers [25]. Malawi, being a developing country and one of the poorest for that matter, is bound to suffer from poor regulatory capability and lack of expertise in routine rigorous medicine testing, considering the heavy reliance on imported anti-malarials. Most international surveys have rarely included samples from Malawi and efforts to locate any such internal activity at the required level have so far proved futile.

\section{Conclusions}

The findings of the study suggest a widespread use of substandard anti-malarial medicines throughout the country with respect to API content. The detection of indiscriminate cases of excessive as well as insufficient API in both artemisinin-based and non-artemisinin-based components can be attributed to improper GMP and lack of quality control in the distribution chain. Therefore, there is an urgent need for regular rigorous testing by the National Medicines Regulatory Authority to deter importers from flooding the markets with poor quality medicines. Despite the effort put in place by the Government and its partners to minimize the impact of malaria over the years, the disease remains the country's biggest health challenge. The post-marketing surveillance and pharmacovigilance system has been under development since 2009 and yet, it is still faced with severe limitations. 


\section{Additional files}

\section{Additional file 1: List and details of anti-malarial medicines purchased. \\ Additional file 2: Figure S1. Map of Malawi showing sampling sites. Additional file 3: Results of HPLC assay for API content in anti-malarial medicines.}

Additional file 4: Detailed analytical results.

\section{Abbreviations}

API: Active pharmaceutical ingredients; ACT: Artemisinin-based combination therapy; ATM: Artemether; ATS: Artesunate; C: Compliant;

DHA: Dihydroartemisinin; EA: Enumeration area; EDQM: European Directorate for the Quality of Medicines and Healthcare; FDC: Fixed dose combination therapy; GMP: Good manufacturing practice; HPLC: High pressure liquid chromatography; LUM: Lumefantrine; NC: Non-compliant; NMCP: National Malaria Control Programme; P: Pyrimethamine; Ph. Int:: International pharmacopoeia; Pp: Piperaquine; PPS: Probability proportionality to size; QN: Quinine; RS: Reference standard; S: Sulphadoxine;

SM: Sulphamethoxypyridazine; SOP: Standard operating procedure; SP: Sulphadoxine-pyrimethamine; SQ-TLC: Semi-quantitative thin layer chromatography; SRS: Simple random sampling; WHO: World Health Organization.

\section{Competing interests}

The authors declare that they have no competing interests.

\section{Authors' contributions}

IAM conceived the study and designed the experiment. IC carried out the sampling and wrote the first draft. IC and DYK performed the experiments. IAM, DOS and JJEK supervised the study. DOS produced the final manuscript. All authors read and approved the final manuscript.

\section{Acknowledgements}

The study was carried out in the laboratories of the Department of Chemistry, University of Ghana Legon. Funding was received from the Department for International Development UK (DFID)/Wellcome Trust through the National Commission for Science and Technology (NCST) Malawi under the Health Research Capacity Strengthening Initiative (HRCSI). We would like to thank Mr. Wilford Mathiya of the Pharmacy, Medicines and Poisons Board (Malawi), Mr. Rage Majamanda of the National Health Sciences Research Committee (NHSRC) (Malawi) and Dr Mathildah Chithila, Dr Happy Phiri, Mr Andrew Mpesi and Mr George Ng'ambi of the HRCSI Secretariat (Malawi) for their prompt assistance(s) during the sample collection exercise.

\section{Author details}

${ }^{1}$ Department of Chemistry, University of Ghana, Legon, Accra, Ghana.

${ }^{2}$ Ministry of Education, Science and Technology, Lilongwe, Malawi.

Received: 31 October 2014 Accepted: 3 March 2015

Published online: 25 March 2015

\section{References}

1. Butler AR, Khan S, Ferguson E. A brief history of malaria chemotherapy. J R Coll Physicians Edinb. 2010;40:172-7.

2. WHO. World Malaria Report 2014. Geneva, Switzerland: World Health Organization; 2014

3. Programme NMC. NMCP: Malaria strategic plan 2011-2015; towards universal access. Lilongwe, Malawi: Ministry of Health; 2011.

4. Ettling M, McFarland DA, Schultz LJ, Chitsulo L. Economic impact of malaria in Malawian households. Trop Med Parasitol. 1994;45:74-9.

5. Dondorp AM, Yeung S, White L, Nguon C, Day NPJ, Socheat D, et al. Artemisinin resistance: current status and scenarios for containment. Nat Rev Microbiol. 2010;8:272-80.

6. Newton PN, White NJ, Rozendaal JA, Green MD. Murder by fake medicines. BMJ. 2002:324:800-1.

7. Nayyar GML, Breman JG, Newton PN, Herrington J. Poor-quality antimalarial, medicines in southeast Asia and sub-Saharan Africa. Lancet Infect Dis. 2012;12:488-96
8. Maponga C, Ondari C. The quality of antimalarials; a study in selected African countries. World Health Organization (WHO) Department of Essential Medicines and Medicines. WHO/EDM/PAR/2003.4; 2003 [http://apps.who.int/ medicinedocs/pdf/s4901e/s4901e.pdf]

9. Staedke S: Medicine safety and quality. London School of Hygiene and Tropical Medicine; Uganda Malaria Surveillance Project. ACT Consortium; 2009. [http://www.actconsortium.org/data/files/ actc_safety_and_quality_overview.pdf]

10. Strengthening Pharmaceutical Systems (SPS) Program: Safety of medicines in sub-Saharan Africa: assessment of pharmacovigilance systems and their performance. US Agency for International Development by the Strengthening Pharmaceutical Systems (SPS) Program. Arlington, VA: Management Sciences for Health; 2011. [http://apps.who.int/medicinedocs/en/d/Js19152en/]

11. World Health Organization: The International pharmacopoeia (including first, second and third supplements). 4th Edition, Version 2; Online, Geneva; 2013. [http://apps.who.int/phint/en/p/about/]

12. World Health Organization. The International pharmacopoeia 4th Edition, Version 2; CD-ROM, Geneva. Antwerp, Belgium: Human Info NGOMIT; 2006.

13. World Health Organization, BTD. Basic tests for medicines: pharmaceutical substances, medicinal plant materials and dosage form; 1998. [http:// whqlibdoc.who.int/publications/1998/9241545135.pdf]

14. World Health Organization. New basic tests for antimalarials. $\mathrm{CH}-1211$ Geneva 27, Switzerland: Quality Assurance and Safety: Medicines (QSM), Department of Essential Medicines and Medicines Policy (EDM), World Health Organization Working Document QAS/06.159; 2006.

15. WHO: Basic tests for pharmaceutical dosage forms. Geneva; World Health Organization, 1991. [http://apps.who.int/medicinedocs/pdf/h1794e/h1794e.pdf]

16. Osei-Safo D, Harrison JJEK, Addae-Mensah I: Validation and application of quality assurance methods developed for artemisinin-based antimalarial medicines to assess the quality of a selection of such medicines distributed in Accra, Ghana. African Journal of Pharmaceutical Sciences and Pharmacy 2010, 1: 1-25. Retrieved from [http://www.ajpspjournal.com/article/view/ 6206]

17. Osei-Safo D, Agbonon A, Konadu DY, Harrison JJEK, Edoh M, Gordon A, Gbeassor M, Addae-Mensah I: Evaluation of the quality of artemisinin-based antimalarial medicines distributed in Ghana and Togo. Malar Res Treat 2014, Article ID 806416, 12 pages. [http://www.hindawi.com/journals/mrt/2014/ 806416/]

18. Ranher SS, Gandhi SV, Kadukar SS, Ranjane PN. A validated HPLC method for determination of artesunate in bulk and tablet formulation. J Anal Chem. 2010;65:507-10.

19. Arun A, Smith AA. Simultaneous HPLC-UV method for the estimation of artemether and lumefantrine in tablet dosage form. Int J Pharma Biomed Res. 2011;2:201-5. ISSN No.: 0976-0350.

20. The United States Pharmacopoeia USP NF 24. Monographs of quinine sulphate and quinine sulphate tablets. Rockville: United States Pharmacopoeia Convention; 2006. p. 1458-60.

21. WHO expert committee. Sulphadoxine and pyrimethamine tablets. Adopted text for addition to The International Pharmacopoeia. World Health Organization Working document QAS/07.218/FINAL; 2011. [http://www.who. int/medicines/publications/pharmacopoeia/Sulfadox-Pyrimeth-tab-QAS07218FINAL.pdf]

22. World Health Organization. Counterfeit drugs. Guidelines for the development of measures to combat counterfeit drugs. Geneva: World Health Organization; 1999. WHO/EDM/QSM/99.1.

23. Bate R, Coticelli $P$, Tren $R$, Attaran A. Antimalarial medicine quality in the most severely malarious parts of Africa - A six country study. PLoS One. 2008;3:e2132.

24. WHO QAMSA. Survey of the quality of selected antimalarial medicines circulating in six countries of sub-Saharan Africa. Geneva: World Health Organization Quality Assurance and Safety; Essential Medicines and pharmaceutical Policies, WHO/EMP/QSM/2011.1; 2011. [http://www.who.int/ medicines/publications/WHO_QAMSA_report.pdf]

25. Caudron JM, Ford N, Henkens M, Macé C, Kiddle-Monroe R, Pinel J. Substandard medicines in resource-poor settings: a problem that can no longer be ignored. Trop Med Int Health. 2008;13:1062-72. 